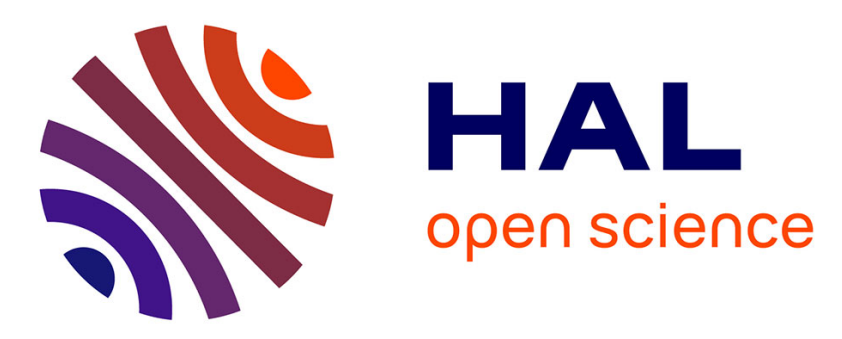

\title{
Assessment and monitoring of the effects of the ComMod approach
}

Pascal Perez, Sigrid Aubert, William'S Daré, Raphaele Ducrot, Natalie Jones, Jerome Queste, Guy Trébuil, Annemarie van Paassen

\section{- To cite this version:}

Pascal Perez, Sigrid Aubert, William'S Daré, Raphaele Ducrot, Natalie Jones, et al.. Assessment and monitoring of the effects of the ComMod approach. Companion modelling, Quae, pp.141-167, 2011. cirad-00844615

\section{HAL Id: cirad-00844615 http://hal.cirad.fr/cirad-00844615}

Submitted on 15 Jul 2013

HAL is a multi-disciplinary open access archive for the deposit and dissemination of scientific research documents, whether they are published or not. The documents may come from teaching and research institutions in France or abroad, or from public or private research centers.
L'archive ouverte pluridisciplinaire $\mathbf{H A L}$, est destinée au dépôt et à la diffusion de documents scientifiques de niveau recherche, publiés ou non, émanant des établissements d'enseignement et de recherche français ou étrangers, des laboratoires publics ou privés. 


\title{
Chapter 6
}

\section{Assessment and monitoring of the effects of the ComMod approach}

\author{
Pascal Perez, Sigrid Aubert, William's Daré, RaphaÈle Ducrot, Natalie Jones, \\ JÉrôme Queste, Guy TrébuIL and AnNemarie Van PAAssen
}

\section{Justifications and assumptions}

\section{Why is an assessment of ComMod needed?}

The assessment of the effects of companion modelling is currently still a theoretical and methodological field under investigation. However, neighbouring fields of research provide relevant elements of reflection. For example, research on integrated assessments aims to provide public policy decision-makers with relevant information for decisionmaking. This information generally arises out of an interdisciplinary process for consolidating, interpreting and communicating knowledge from various sources (Hisschemöller et al., 2001). In this context, Siebenhüner and Barth (2005) tried to determine under what circumstances the use of a model would be consistent with the objectives of a participatory approach. It should be stressed, however, that there is a marked difference between an integrated assessment using certain forms of modelling and the ComMod approach itself. Hisschemöller et al. (2001) considered that the aim of integrated assessment is to inform the parties involved without seeking to promote convergence of opinion. As discussed in Chapter 1 and in more detail in Chapter 5, the ComMod approach, by contrast, seeks to support the sharing of views, the consensual exploration of scenarios and, where appropriate, group decision-making. From an approach assessment standpoint, it thus seems necessary to go beyond analysing knowledge creation and learning processes and also focus on interaction and mobilization processes, or even legitimacy and accountability principles to provide an understanding of 'what happens' during a ComMod approach and what are its consequences. 
Trying to establish an assessment protocol, which is both scaled to the implementation contexts of the ComMod approach and sufficiently robust to cover all the aforementioned analytical dimensions, is quite a challenge. Expecting to create a perfect protocol at the first attempt is just wishful thinking. The protocol created for, and used during, the ADD-ComMod project corresponds to a first draft of a more advanced assessment methodology, the initial stages of which are presented at the end of this chapter. Within this project, the objective of the assessment process is initially twofold:

- to estimate the impact of the approach in terms of mobilization and involvement of local stakeholders in group learning and decision-making

- to improve the ComMod approach's underlying methodology and theory.

The second goal probably influenced the structure and content of the assessment protocol presented later in this chapter. As each structure has its own constraints, it is likely that the proposed format limited the assessors' ability to answer the questions raised by the first goal as much as they would have liked. However, the comparative nature of the ADD-ComMod project (27 case studies) imposed a methodological rigour called for by the diversity of the case studies and the assessors themselves.

\section{Theoretical foundations}

This involves jointly mobilizing the theoretical foundations for using the models and the participatory approaches used to structure the assessment. The question is to identify how and at what stage the combination of modelling and participation is meaningful. To build an assessment framework, it thus seems essential to identify the specific methodologies and tools used during a project, and highlight their ability to fulfil the expected functions and to achieve the desired goals.

This assessment approach draws on the work of Webler (1999) who proposed a 'craft-theory-dialectic' as a means of advancing the field of public participation. According to Webler, what is required is to implement a practice that can learn from theory and a theory that draws on practice. Similarly, the ComMod approach is characterized by an empirical richness, which, on the basis of successive approximations, can bring about a more widely accepted solution. According to Webler (1999), to advance the field of public participation it is important to go beyond the answer to the question of 'what works?' and look at 'why does it work?' and 'and how could it work even better?' The mainstreaming of these two issues provides a link between theory and experience on the ground. Indeed, the case studies to be assessed differ according to a number of criteria, but share the same theoretical principle, that is, companion modelling. This theoretical foundation makes it possible to compare how these assumptions behave in practice as experienced by both the designers of the approach and the participants themselves.

Before describing the background of the assessment protocol proposed in the ADD-ComMod project, consideration should first be given to other theoretical foundations used by some assessors, in addition to the common protocol. These contributions have sometimes been deemed necessary to provide a better response to the first assessment objective concerning the mobilization and group decision. In general, these contributions stress the need to implement an assessment during the course of the process so as to adhere as closely as possible to the participatory process itself. The assessment then becomes a reflexive exercise with the project participants and designers relating to both 
approach procedures and its purposes. The 'most significant change' method, proposed by Davies (1998) and Dart (1999), is briefly presented in Box 6.1.

Without denying the obvious interest of this approach, it is useful to recall that almost $80 \%$ of the case studies were assessed in the context of an ex post procedure, sometimes two years after the project concerned. An example of the common protocol enhanced by some assessors is presented later in this chapter.

\section{Box 6.1 - Most significant change.}

The most significant change method calls for the players on the ground (including researchers) to indicate their experience or observations about a change (positive or negative) deemed significant in a specific area (e.g. knowledge acquisition, perception of the other stakeholders, changes in behaviour or practices, etc.) during the process undertaken and explain why. After indicating their experience, the participants in a plenary session choose the issues considered to be most relevant in each of the areas considered to draw the research team attention to this specific point. The research team is then required to take action on this point and scale its approach in the direction desired by the stakeholders on the ground. This type of monitoring/assessment of the effects of the process seems appropriate for the ComMod approach and should be carried out iteratively in support of the successive cycles of activity;

According to the changes observed and identified, such an approach may lead the team to re-consider its objectives. Above all, it provides them with a better understanding of the effects of the group process on the various stakeholders, and allows them to explore and share the values and preferences involved. Finally, this technique allows the group to understand what is or is not obtained by the process, to clarify what is really wanted and accordingly to define its next steps to move in the desired direction. The benefits of the technique are as follows (Davies, 1998, Dart, 1999).

- It is not based on 'objective indicators' that may control or ignore the diversity of knowledge, values and interests.

- It does not measure or list general experience but instead seeks to identify what is exceptional, surprising and a source of inspiration.

- It does not normally define indicators, as in-process learning is more deductive than inductive; it is a question of learning from recent events and keeping an open mind.

- The analysis is carried out and the indicators are defined by the participants rather than by the researchers.

- Dense contextual descriptions about complex and uncertain processes are more informative than statistics.

Conventional assessment methods stimulate the ritual performance of tasks, while the technique gives rise to new ideas for learning and tailoring in relation to new areas of interest and changing situations.

After Dart (1999)

\section{Background of the assessment protocol}

The proposed assessment protocol is based in part on the 'theory-based evaluation' paradigm, which focuses specifically on the identification of a project's rationale. It provides a deeper understanding of the functioning of a project and allows priorities to be assigned to the issues requiring further attention (World Bank, 2004). This paradigm implies that the vast majority of projects observed are based on an implicit or explicit theory explaining how and why such a project should succeed (Curnan, 1998). 
An examination of the various case studies within the ADD-ComMod project should show how the ComMod approach and its results vary in different contexts. This comparison should make it possible to identify patterns and critical factors in the group-learning and decision-making process. The application context, that is, the visibility or urgency of certain biophysical dynamics on the one hand, and socio-political arrangements on the other, significantly influences the ComMod approach. It is essential, therefore, for the assessment framework to consider all ComMod activities and their effects in their context.

The first step in the process for creating a multi-site analysis framework is to identify a comparison subject and measurement units. Several authors have focused on the problems associated with the conceptual boundaries of scientific projects on sustainable development because of the complexity of the socio-ecosystems considered (Cash et al., 2006; Reed, 2008). The limits of these projects are often vague in terms of their scope and duration. It is often difficult to know when a project starts and stops. Assessors need to have specific knowledge of the time, space and subject limits of what they are supposed to observe. The importance of this initial focus increases when the diversity factors between the case studies of the ADD-ComMod project are considered:

- the diversity of participatory modelling techniques

- the various problems and controversies considered

- the interdisciplinary nature of the projects

- the use of assessors from several disciplines and cultures

- the stages of maturity of projects, with some still under construction, while others have been completed for several years.

To clarify the purpose of our study, a question should be asked: what are the common points between all these participatory modelling projects? A first common point is the scientific approach. The assumption made is that all the cases studied share a set of theoretical assumptions underlying their procedural rationale. These assumptions are based on concepts related to participation, the use of mediation tools, and group-learning and decision-making. Such assumptions are interpreted within social, institutional, political and environmental contexts. It follows that the way the process is structured to a certain extent reflects this underlying rationale. A project includes sequences during which tools and methods are implemented in a specific context. The proposed assessment protocol is thus based on:

- the project context (including the goals to be reached)

- the process (methods and tools used)

- the underlying theoretical foundations.

In this context, the assessment seeks to understand why the approach designers used certain methods and artefacts, and then analyse how these assumptions were interpreted and translated at the implementation level. Common assumptions can be analysed in different contexts by comparing the experiences of both designers and participants. An assessment based on the theory is not limited to assessing a project's outcome and consequences. It also establishes a bridge between the two describing how in practice some activities contribute to certain achievements and impacts (Patton, 1990). It is important to note here that the ComMod approach does not normally have an action plan. The action plan is actually designed and adapted along the way. This strategy allows certain unexpected side effects to be taken into account in the development of the process. 
It seems difficult to establish a protocol that provides both an overview of many cases of highly diverse studies and the mainstreaming of contextual type adaptations. A theory-based assessment calls for the developing of a model - or an image - of the project rationale explaining how it works. Argyris, quoted in Patton (1990), refers to the 'professed theory' to describe what designers would like to see happen during the project, as opposed to the 'theory in practice', which describes what happens in reality. The proposed assessment protocol seeks to define the professed theory by working with designers and identifying the sequence of methods used and their expected effects (steps). The theory in practice is defined by questioning participants and designers to establish what actually happened in practice. One of the main objectives of assessment is thus to identify, characterize and explore these 'influential factors' to advance the field of companion modelling (Figure 6.1).

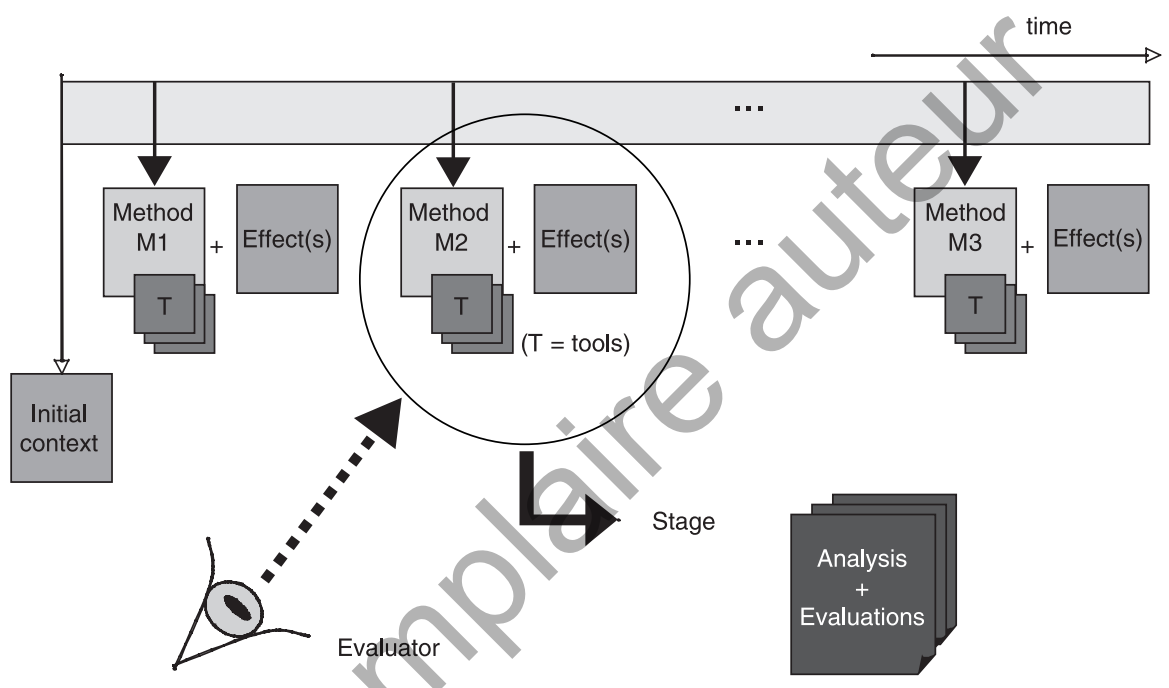

Figure 6.1. The implementation of the ComMod approach.

\section{The assessment protocol}

\section{Description of the assessment protocol}

The proposed assessment framework, known as the Canberra Protocol (CP), consists of two parts, the designer questionnaire (DQ) and the participant evaluation guide (PEG). The first part aims to capture the experience of the design team, including the theoretical rationale underlying the projet (see Box 6.2). The second part guides the information gathered on the experience of the participants. The theoretical rationale determines the professed theory as defined by Argyris (in Patton, 1990). The experience of both the team of designers and the participants is used to rebuild the theory in practice. Table 6.1 summarizes the data-gathering methods that can be used to inform the CP. 
The DQ defines the information to be gathered from the project team. It is entered by the assessor from the project documents and existing reports and completed during interviews. The project documents provide the assessor with a good overview and detailed information on the project context. Direct observations by the observer can also be used in the case of ongoing projects. The DQ includes two subcomponents: the 'context' and the 'process'. Figure 6.2 shows a diagram of this questionnaire.

Table 6.1. Methods for gathering data to define the Canberra Protocol.

\begin{tabular}{lll}
\hline Canberra Protocol elements & Professed theory & Theory in practice \\
\hline Designer questionnaire & Interviews with designers & Interviews with designers \\
Designer views & Project documents & Project documents \\
& & $\begin{array}{l}\text { Direct observations (ongoing } \\
\text { projects) } \\
\text { Previous assessments }\end{array}$ \\
Participant evaluation guide & Participant surveys \\
Participant views & Previous assessments \\
& Informal interviews (ongoing \\
& projects) \\
\hline \\
Designer's questionnaire
\end{tabular}

Each project takes place in a social, political and economic context, which influences its design, functioning and results. Knowledge of these parameters is crucial to understanding the why and how of the project components. In the natural resources management field, the site's socio-political situation and physical configuration are key aspects of the decision-making process. The ComMod approach itself focuses on identifying the interactions between environmental and social dynamics. The DQs 'context' section looks at the relevance of the participatory modelling procedures with regard to certain socio-political and physical environment situations. The project's initial objectives are also important in informing the assessor of the project's initial intention. Finally, the assessment determines the relative influence of tools and methods to achieve these goals. To this end, the DQ also focuses on the project team's justification for the adoption of a participatory modelling approach. This contributes to validating the theoretical assumptions underlying the ComMod approach and the participatory model in general. The assessor may also make use of this justification in interviews with participants to update the relationships between professed theory and theory in practice.

\section{Process}

This part of the DQ provides a systematic record of the project's structure and sequencing of the methods used. The project team and assessor work together to restructure the succession of events as a series of methods (or steps). In some cases, this breakdown and the identification of a beginning and an end can be difficult. The project's rationale is based on this series of methods. The aim of this section is to identify the critical blocks that had a significant influence on the project workflow. Once these blocks 
are identified, their internal functioning can be focused on through global research issues. The blocks are also used to guide interviews with participants on the basis of the PEG (see below). Finally, any differences between activities carried out, theoretical assumptions and results (as perceived by participants and designers) can be identified and studied at block level.

\section{Box 6.2 - Applying the Canberra Protocol. Case study of Tarawa, Republic of Kiribati.}

The project was developed on the Tarawa Atoll, capital of the Republic of Kiribati (South Pacific), in 2004-2005. The main goal was to resolve a conflict between the government and indigenous landowners over the management of groundwater stocks. These stocks are made up of small freshwater lenses and are very sensitive to any type of contamination. The project was initiated by a deep ethnographic study and progressed to the design of a computer role-playing game. Then, role-playing games involving landowner representatives and government agencies lead to collaborative scenarios of participatory management of water reserves. Nevertheless, the upheaval of contradictory government stands undermined the whole process.

The evaluation of this study case took place at the beginning of 2007, two years after the end of the project (ex-post evaluation). First, the evaluator that had been involved in two other evaluation processes, went through the documents and papers redacted by the leaders of the evaluation group. Then she adapted the designer questionnaire before interviewing the two main facilitators of the ComMod process. This preliminary study required one week of work, plus five hours for the interviews. Sequencing the timetable of the project into steps (method + effects) permitted the definition of the collective key moments. With the agreement of the facilitators, the evaluator decided to focus her inquiry on the ethnographic interviews and the role-playing game. An open questionnaire was elaborated to cover the main topics of the designer questionnaire while taking into account the local socio-cultural context.

In February 2007, the evaluator spent a week in the Tarawa Atoll to interview 13 participants, with the help of the previous local responsible for the project. The landowners were interviewed at home and in their native language (I-Kiribati). Representatives of the government were interviewed at their office in English. Each interview lasted approximately one hour. Despite the long delay after the end of the project, participants felt comfortable with the content of the enquiry, but the time span significantly influenced the accuracy of their judgements. The necessity of using an interpreter also limited the capacity of the evaluator to go deeper on specific key points.

The final evaluation report was published in September 2007, after several discussions with the facilitators of the ComMod process.

The use of mediation tools (or models) plays a central role in a participatory modelling approach. This aspect of the CP is based on a similar initiative, known as 'harmonizing collaborative planning' (HarmoniCOP) (Mostert et al., 2007). An important part of this work includes the deployment of a framework for assessing the contribution of information and communication technologies as part of participatory processes. Some elements of the HarmoniCOP framework have been included in the CP because of common assessment objectives. The project team is thus required to explain why each method or tool was used and assess certain criteria arising out of the literature on HarmoniCOP (Maurel et al., 2007). These criteria are grouped into three topics as shown in Figure 6.2. 


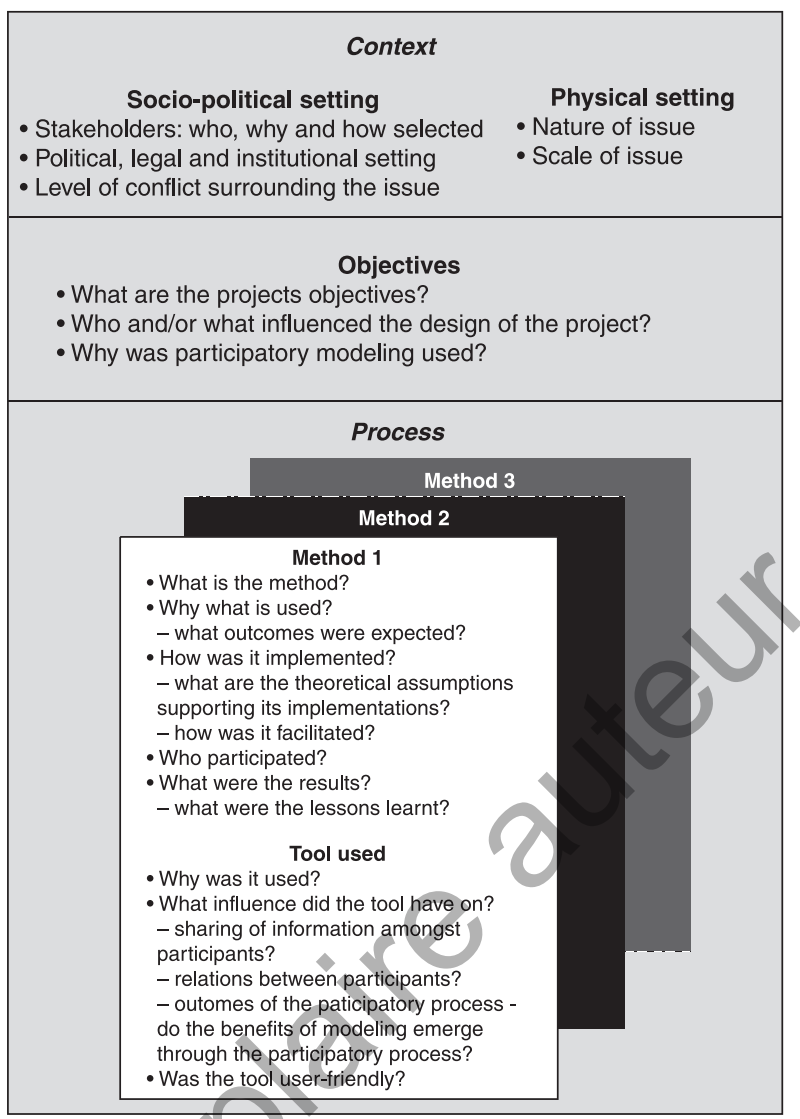

Figure 6.2. Designers Questionnaire (DQ).

\section{The participant evaluation guide}

The PEG assists the assessor in establishing his investigation. It suggests what information should be obtained from the participants to understand their experience of the participatory modelling process. This PEG organizes the responses in the same structure as in the DQ, allowing the responses of participants to be compared with those of the designers. This allows the establishing of a consistent picture of how a participatory modelling initiative takes place from the standpoint of all participants. The survey conducted by the assessor, the formulation of questions and the conducting of interviews depends greatly on the social and cultural context and technical terms. The PEG thus only provides a guide for interviews and leaves it to the assessor's initiative to tailor the formulation of questions and the survey plan to the requirements on the ground (Figure 6.3).

Due to its symmetry with the DQ, the PEG can provide information about what the participants think of the context surrounding the project: what were the aims of this project, who was involved, and why. In terms of procedure, the interview to be conducted is structured by the succession of blocks identified by the DQ. What is of primary interest here is to know what participants appreciated or not, and what benefit it was to them. 


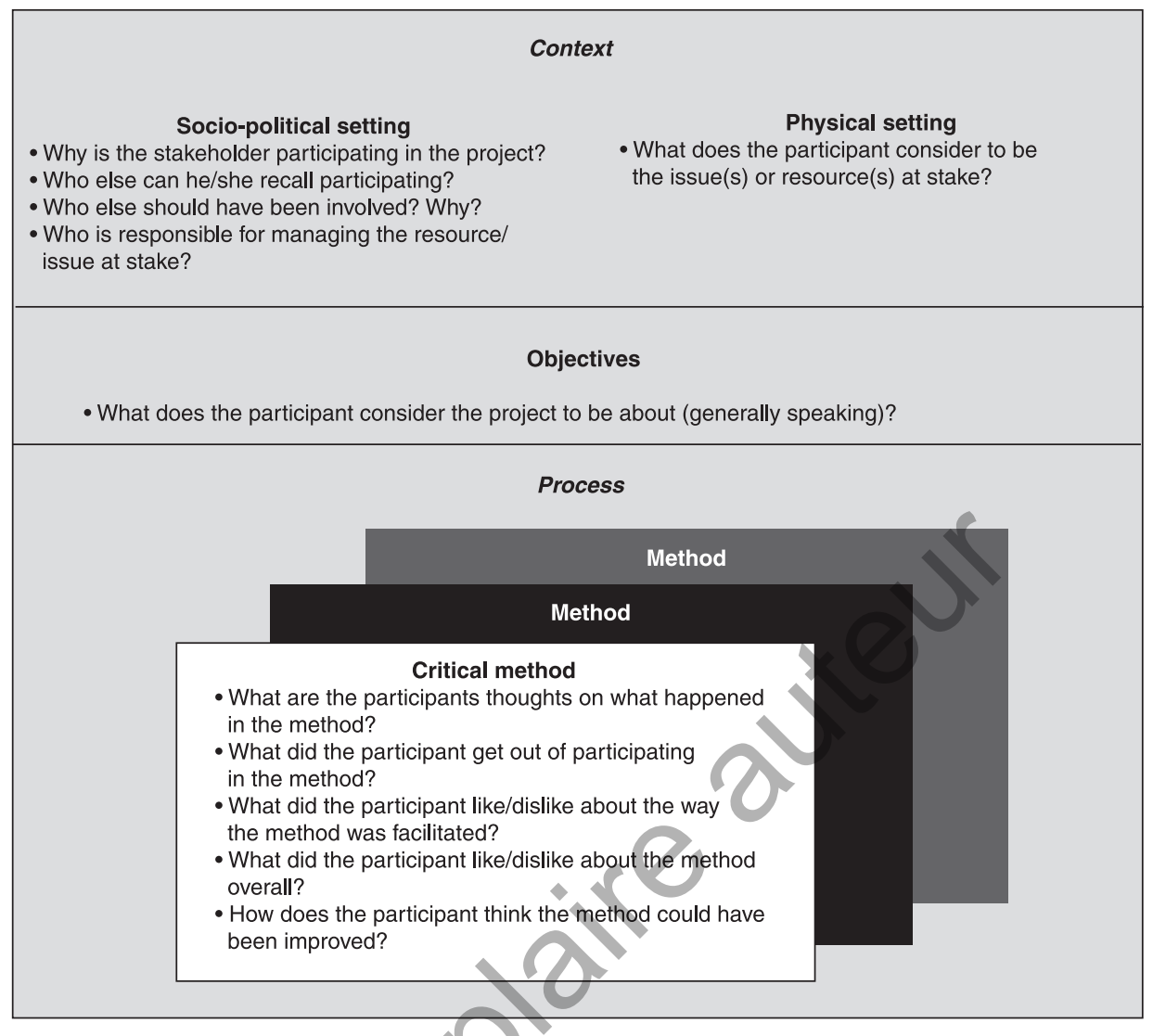

Figure 6.3. Participant Evaluation Guide (PEG).

\section{Description of the assessment guide}

The assessor's guide (Aubert and Perez, 2007) has three objectives:

- to provide assessors with the subjects and criteria to be used to guide their analysis of the documents and information gathered

- to ensure consistency between individual assessments and between the contractual requirements of the ADD-ComMod project

- to create a structure common to all the individual assessments.

With regard to the first point, it should be remembered that the $\mathrm{CP}$, which acts as a methodological guide for implementing each assessment, does not contain any actual assessment criteria. The assessor's guide thus provides the key topics for using the information taken from the CP. This dichotomy between tools and criteria could frustrate the assessor if the wealth of material gathered could not all be put to good use at the level of the assessment subjects. However, it is important to note that all the material available for each project (CP, but also the description outline) can be reused later for further analysis.

With regard to the second point, one of the main challenges from the start of the ADD-ComMod project was to keep overall consistency as high as possible. Twenty seven 
projects dealing with various environmental issues in different countries and in various institutional contexts do not lend themselves easily to a unified analysis, especially as the assessments were divided among a dozen experts with very different profiles. Over and above a common methodology (CP), it, therefore, seemed essential to provide a focus document ensuring consistency between the various assessment reports. It also was essential to ensure that the assessments provided the information needed to meet the contractual requirements of the ADD-ComMod project.

With regard to the third point, the volume of information gathered through all the assessments was intrinsically very large. In view of the time allotted and the human and material resources available, the use of a common format ensured optimum management of resources.

\section{Adapting the Canberra Protocol}

\section{Limits of application}

The assessment protocol (CP) provided a generic framework to allow the 27 case studies identified to be compared. The assessment of each case was delegated to an external assessor. In the end, 11 external assessors were able to implement the protocol and draw up 18 assessment reports. Other cases could not be assessed.

The entry point in the assessment protocol is the assessment guide, which lists the material available to the assessors and provides a procedure. This guide suggests a twostage approach, first involving conducting a survey with the designers (DQ) and then a survey with the participants (PEG). In contrast with strict recommendations for the designer's questionnaire, the survey with participants gives the assessor a large autonomy to define the format and context of the interviews. With regard to the initial guidelines, the 11 assessors can be divided into three groups:

- three assessors followed the guidelines (seven assessments)

- four assessors modified the protocol and justified the changes made (five assessments)

- four assessors changed the protocol without justification (six assessments).

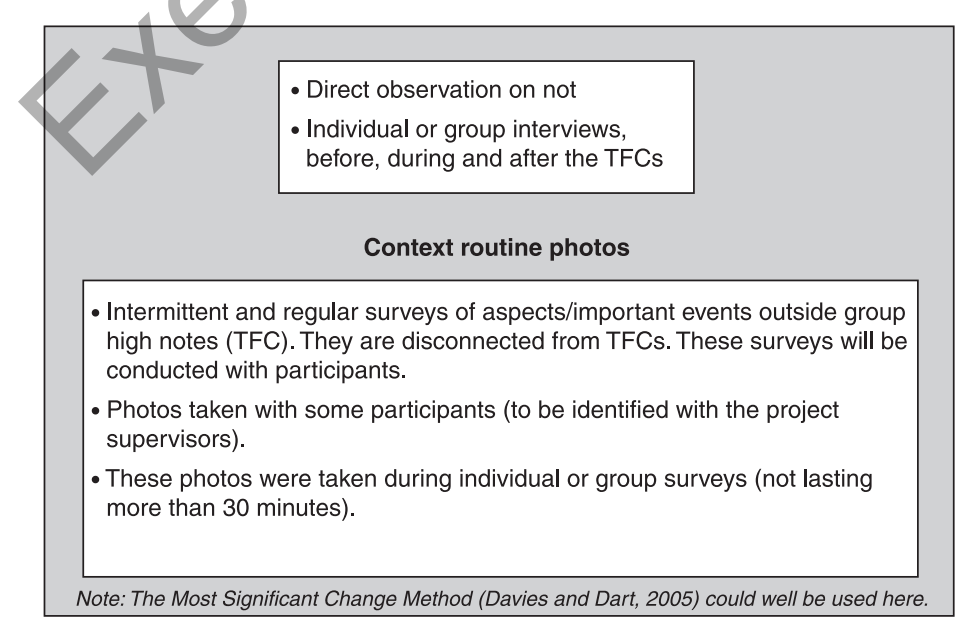

Figure 6.4. Structure of a ComMod process monitoring/assessment protocol. 
Finally, the assessor's guide requested from each assessor a critical feedback on the assessment protocol itself (Figure 6.4).

\section{An example of adaptation}

One assessor (two assessments) considered that the aim of the ComMod approach should be taken into account when defining an appropriate assessment methodology. According to this assessor, the $\mathrm{CP}$, based largely on integrated assessment methodologies, is not sufficiently tailored to assessing the ComMod approach as not enough importance is attached to measuring any improvement in communication and relationships between stakeholders and their capacity for collective action. As a result, the assessor suggests using Leeuwin's (2004) learning and negotiation of innovations theory, and Vermunt's (1998) education theory, which outlines the cognitive, emotional and mega-cognitive dimensions, while incorporating those contained in the CP.

- Cognitive learning: learn about and discuss the aspects and dimensions of the problem examined, create a sense of urgency and identify possible solutions.

- The use of solidarity and group commitment principles: this requires a good understanding of the situation and individual values and interests, particularly by the facilitator, and the commitment to a group standpoint.

- The assessment of group legitimacy used to solve the problem in relation to other stakeholders, and through the use of the ComMod approach.

\section{Results from completed assessments}

\section{Meta-analysis framework}

From the 27 initial projects, 18 assessments only were completed. In accordance with the terminology used in the CP, the ComMod approach consists of a series of methods making use of possible artefacts. These methods sometimes correspond to group high points, the effects of which may be useful to assess. The set consisting of a method and its effects (positive or negative) is then called a milestone, as shown in Figure 6.1.

The assessor's guide (Aubert and Perez, 2007) thus asked assessors to identify these high points and their effects on the basis of the surveys conducted with designers and participants. Assessors were not asked to classify the risks and opportunities associated with these milestones on the basis of a pre-established interpretation framework. This operation was handled in the phase during which a comparative analysis of the 18 assessment reports was carried out. This meta-analysis involved the semantic coding of the reports based on the following seven categories of effects: knowledge creation (S), changing perceptions (V), assistance in interaction with others (I), changing practices $(\mathrm{P})$, independence $(\mathrm{A})$, legitimacy $(\mathrm{L})$ and creating a discussion forum (E). This coding was carried out manually in the semantic database containing about 600 comments in six categories cross-referencing the sources of information (i.e. participant, designer or assessor) and the judgement value made (i.e. favourable or unfavourable). The aim of this relatively cumbersome procedure was to identify any potential invariants in the ComMod approach and subsequently feed into a generic conceptual model of the approach. 
Before discussing the results, it is essential to note that the analysts had a crucial role to play in creating typologies. Indeed, as each assessor used their own nomenclature, it was essential to unify these different descriptions of the stages within a single typology.

After some hesitation, seven categories were selected:

- identification workshop (AI)

- field surveys (ET)

- designing workshop (AC)

- modelling workshop (AM)

- model validation workshop (AVM)

- role-playing workshop (AJR)

- prospective workshop (AP)

\section{Results from the meta-analysis}

\section{Assessment approaches}

This section provides an overview analysis of 18 assessments conducted during the ADD-ComMod project (Tables 6.2 and 6.3).

Of the 18 assessments implemented, most (13) were conducted after the project (ex post). Only four case studies were assessed along the way in real time. In half the cases, the assessment took place more than a year after the project. These two aspects limited both the quality of the information gathered from the participants and the ability of the CP to record detailed information about the process under way.

The assessments were conducted by 13 experts with contrasted profiles, six had fewer than 10 years of experience in their field and the other seven could be considered as senior experts. The experimental nature of the $\mathrm{CP}$, together with the study contexts and their individual disciplinary benchmarks, called for some assessors to make significant changes to the proposed assessment protocol (10 cases) or to the structure of the report itself (five cases). Finally, it is worth recalling that six assessors had not signed the ComMod Charter, and could thus be considered as outside experts.

\section{Creation of legitimate discussion forums}

The discussion forums created by the ComMod approach and to which the participants were committed are definitely the strengths of all the projects assessed (Table 6.4). The role-playing workshops appeared to be a particularly effective way of ensuring interaction between stakeholders. They also contributed to the mutual understanding of the issues and acceptable options for the management of natural resources.

The initial legitimacy of the key participants in nearly all the projects lies in their ability to inform other participants (16 cases), make use of resources (15 cases) or manage resources (16 cases) (Table 6.5). During the project, problems of legitimacy within the group appeared to be recurring but also limited in importance (11 cases). Put another way, the question of legitimacy seems to focus mainly on the absence of players considered, retrospectively, as being critical to the debate (17 cases).

The friendly (14 cases) and innovative (14 cases) nature of the methods used is a key factor in the cohesion of the groups created (Table 6.6). Conversely, the instrumentalization of the process (eight cases) or the limitation of technical options (eight cases) constitute barriers to cohesion. 


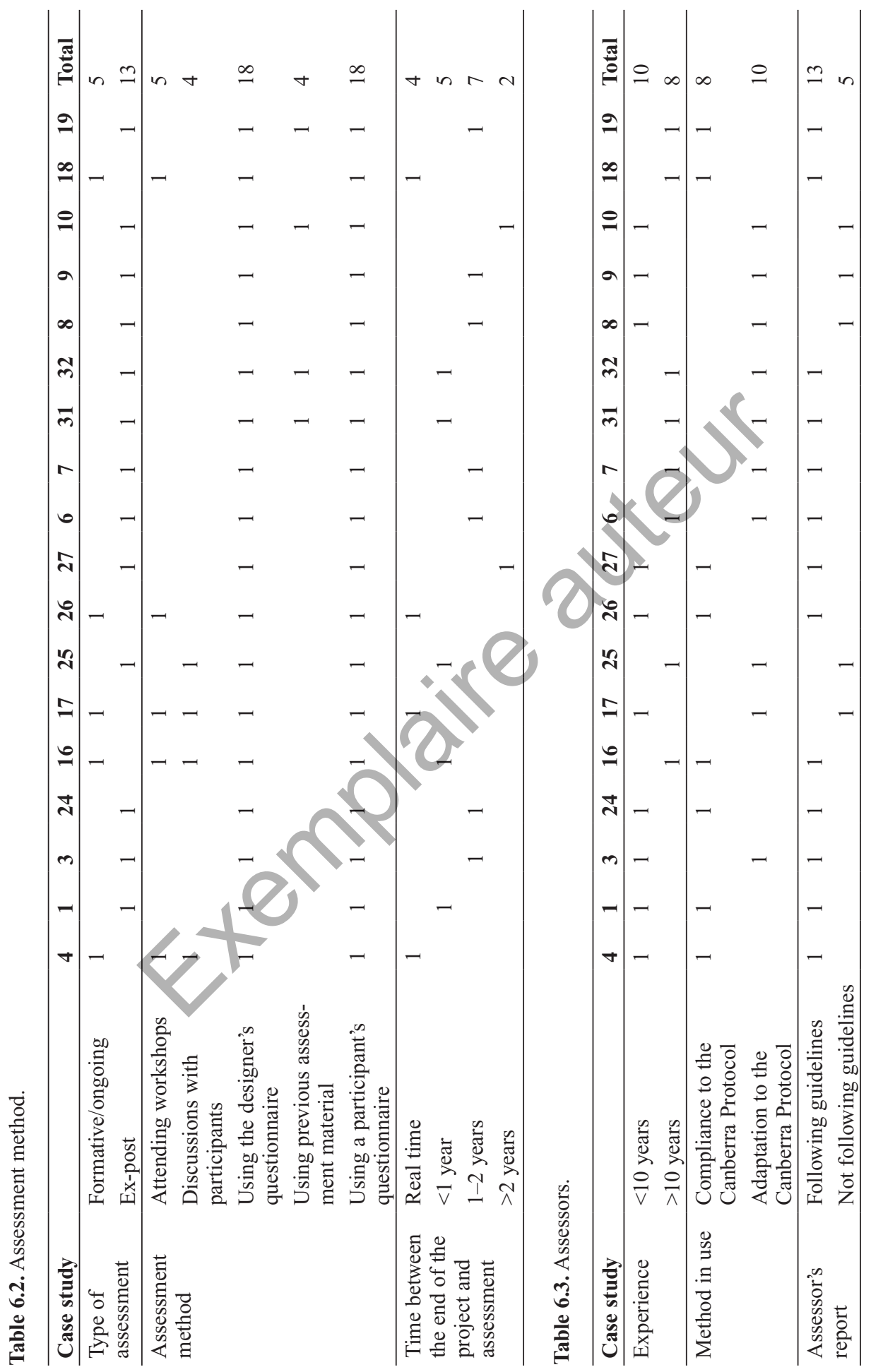




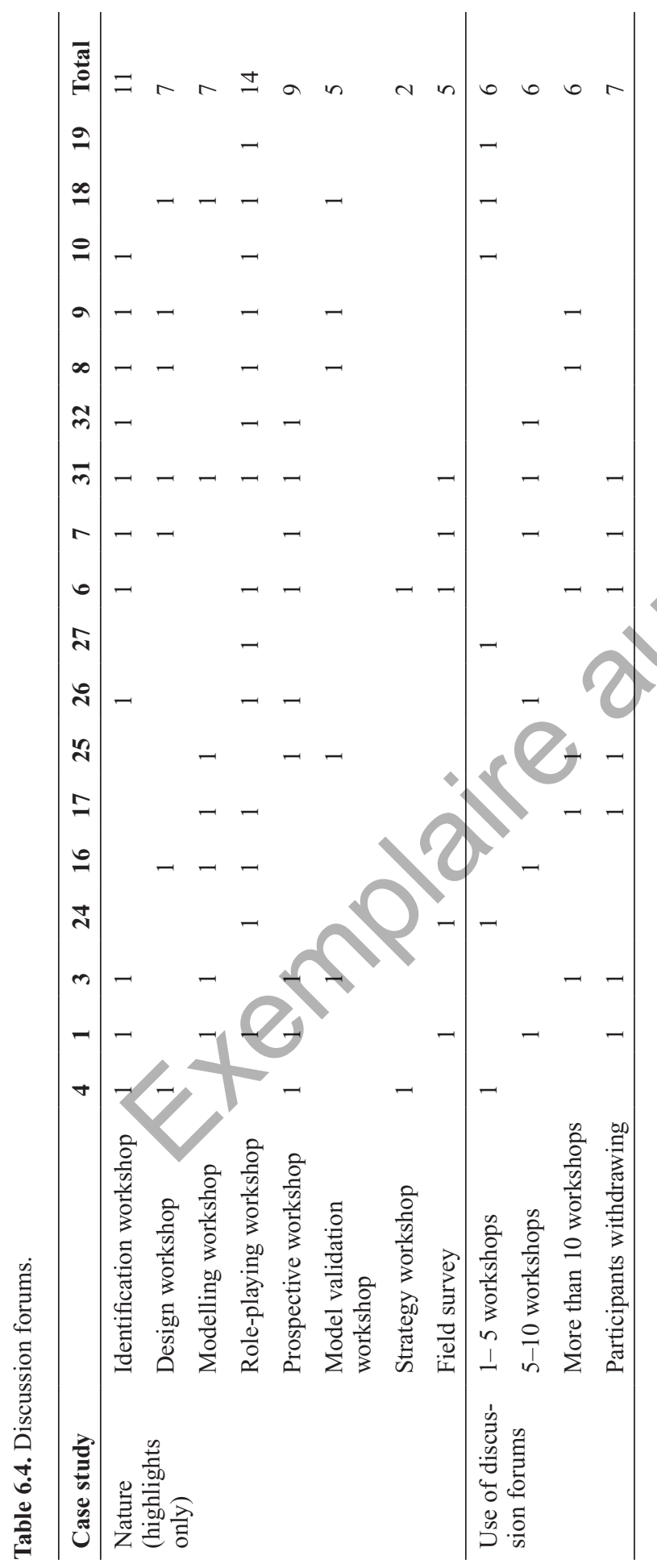




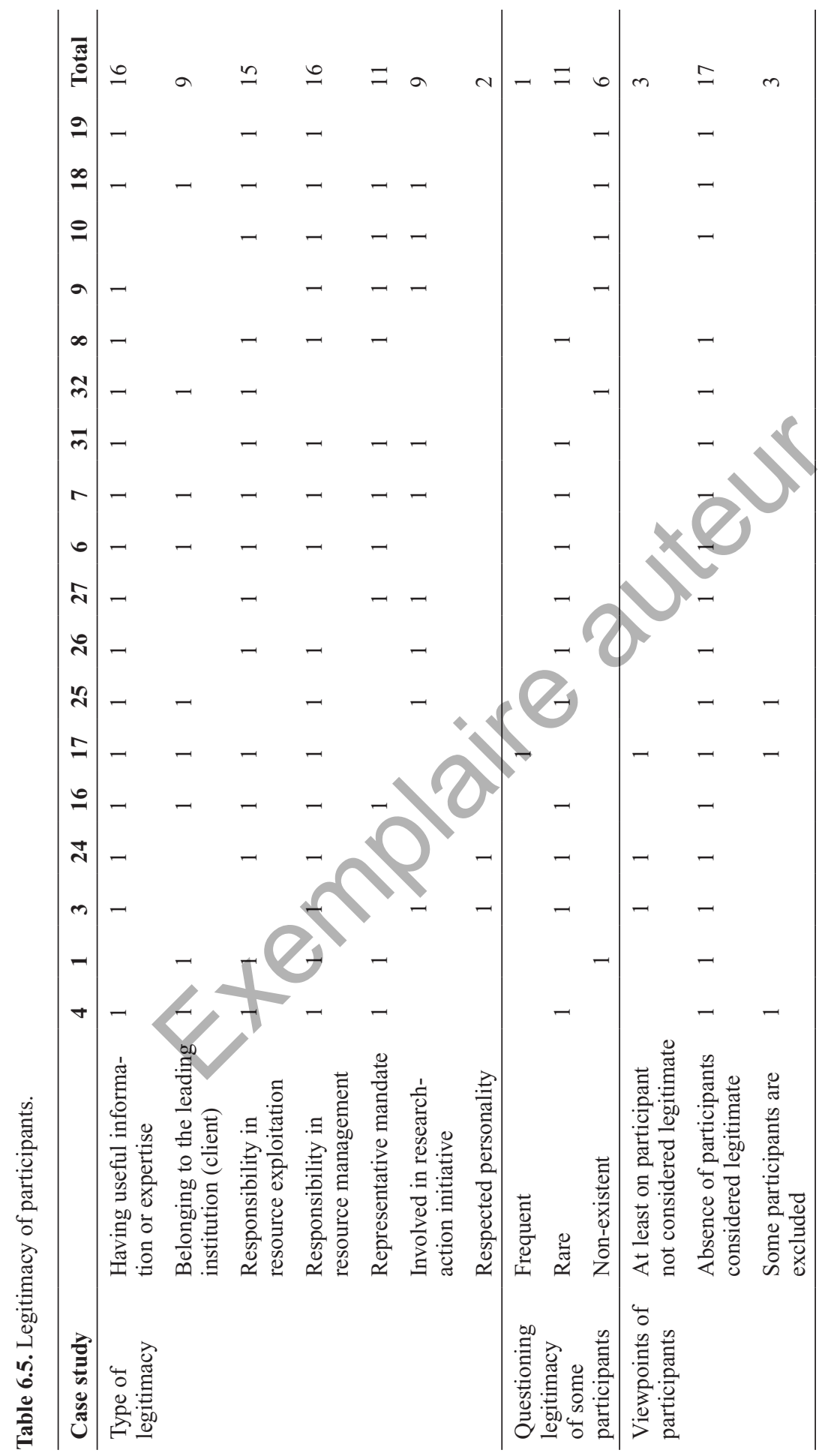




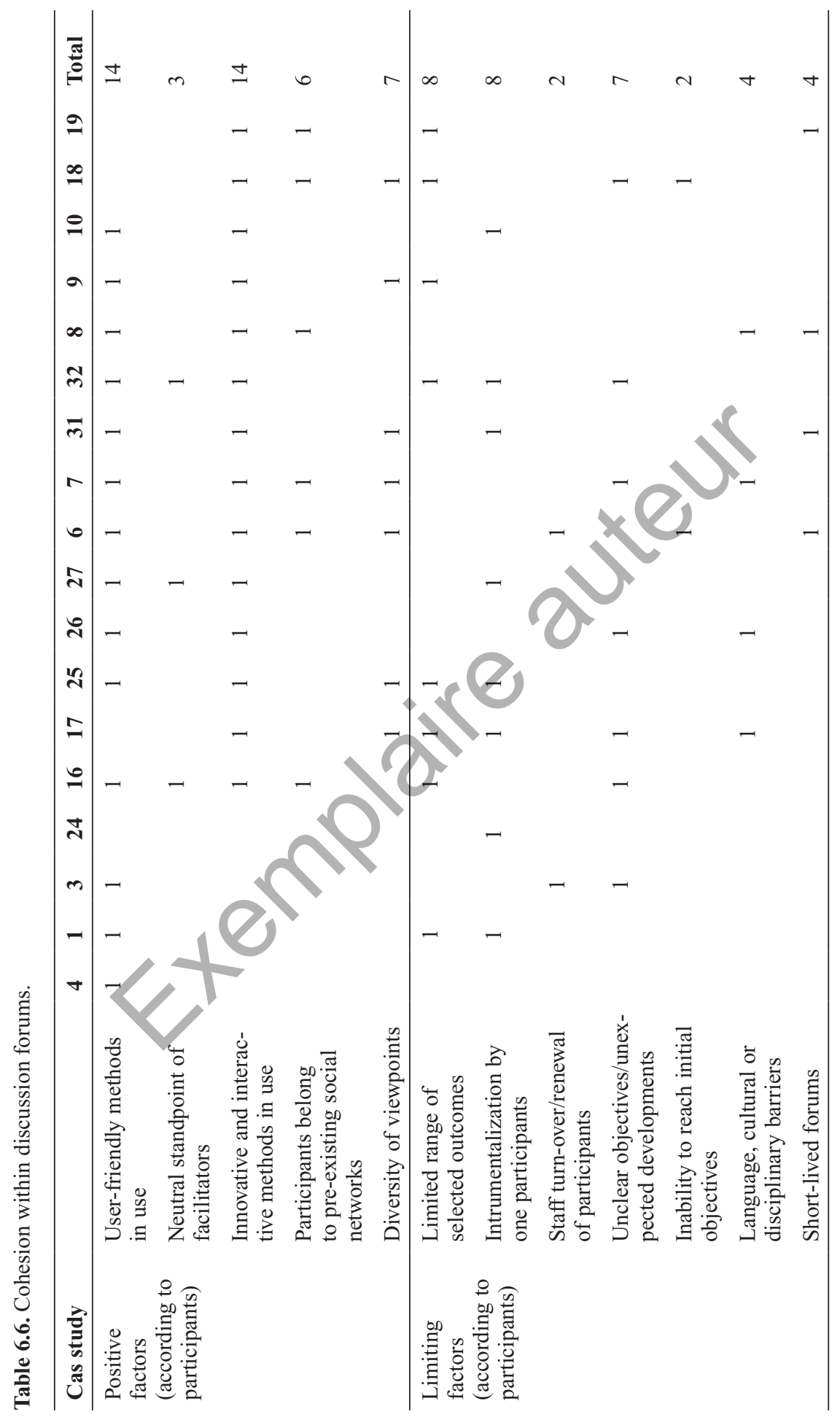


In almost all cases (17), the methods proposed by the ComMod designer were considered as exogenous by participants and other co-designers (Table 6.7). The role-playing or simulation model creation phases were often seen by the commodian as periods during which the consolidation of the information is checked (10 cases). However, the innovative nature of the approach (10 cases) and the remarkable efforts made as regards transparency (12 cases) contributed to minimizing the negative impact caused by the two preceding points.

In short, the ComMod approach thus appears to be synonymous with quality in a participatory process allowing a group of stakeholders to formulate a shared vision of the issues and acceptable options for the management of natural resources.

\section{Perceived advantages and limitations of the ComMod approach}

Table 6.8 summarizes the comments made by the assessors themselves and the comments gathered from designers and participants. The advantages and limitations of the ComMod approaches implemented were broken down into seven categories of results (see above). The measurement unit used was the total number of comments attributed to participants, designers or assessors during the meta-analysis of all the assessment reports (see below).

Logically enough, the creation of knowledge (88) and discussion forums (71) attracted a large number of favourable comments. Support for interaction with other participants (50) was also a strong point of the approach. Broadly speaking, the negative comments related to problems of legitimacy (65): legitimacy of the approach, tools, certain participants, the issue discussed or the solutions recommended. Paradoxically, the creation of the discussion forums (49) also drew criticism, often as a result of the frustration felt by some participants towards a participatory process that was limited both in time and in its ambitions.

It is sometimes difficult to establish with certainty the nature of the products generated through a ComMod-type iterative participatory approach (Table 6.9). Easily identifiable products, such as publications and computer applications (simulation models), may suggest that the ComMod approach is purely an academic exercise. In fact, the other three products identified (i.e. management agreement and formalizing a new group or project) concerned 11 out of the 18 case studies assessed.

In 14 cases, some participants expressed the desire to continue the ComMod approach on the same territory or in new situations (Table 6.10). However, the replication process was hampered by the major restriction of the ComMod approach, that is, the participants' lack of independence (16 cases). The specific issue of the contribution of the ComMod approach to sustainable development is discussed in Chapter 8. 


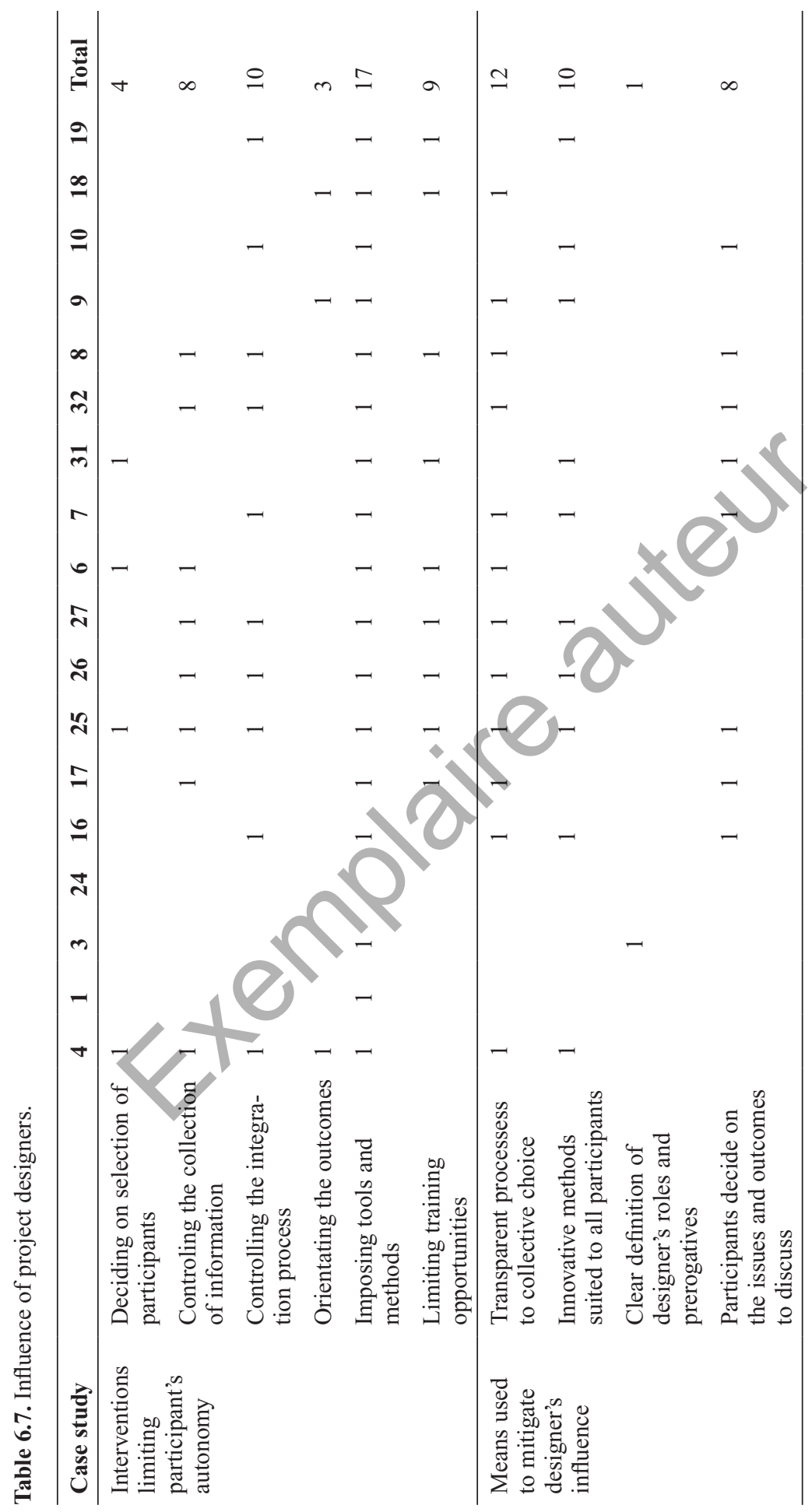




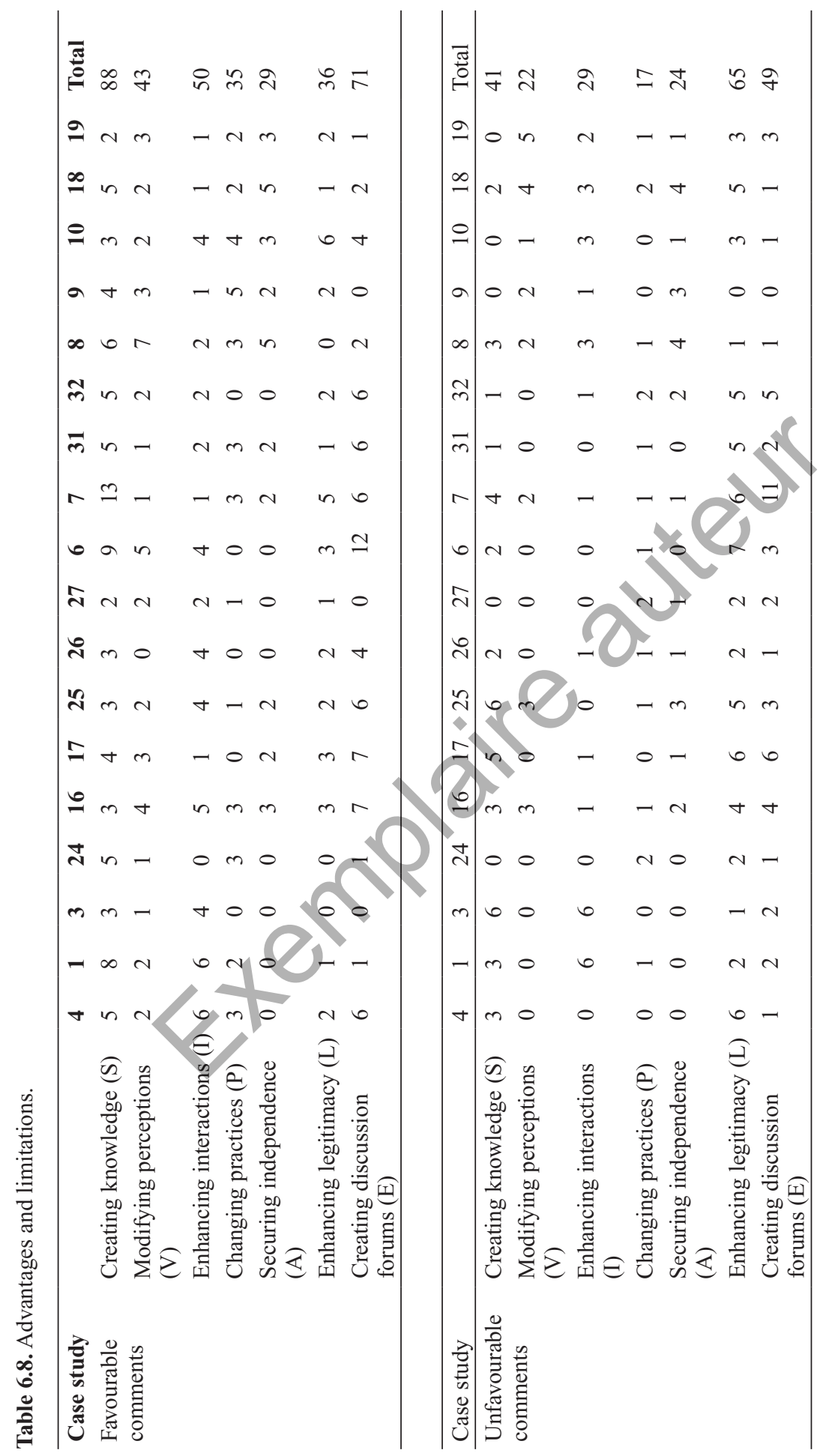




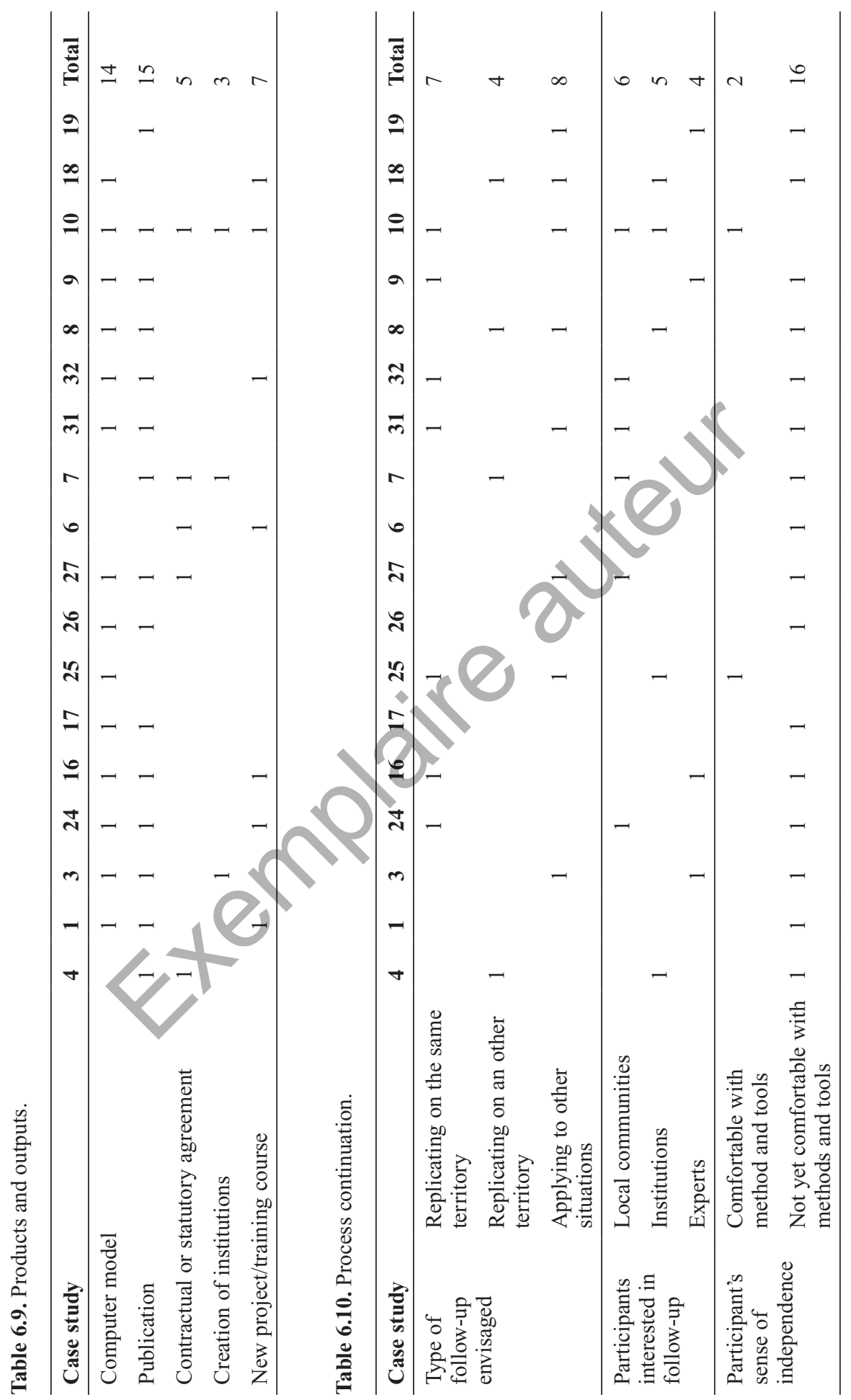




\section{Advantages and limitations of the participatory methods used}

Table 6.11 shows the nomenclature used in the overview table describing the various methods used (workshops) and their effects.

Table 6.11. Nomenclature used to describe methods used and their effects.

\begin{tabular}{ll}
\hline $\mathrm{P} /+$ : positive effect according to participant & $\begin{array}{l}\mathrm{P} /- \text { : effect to be improved according to } \\
\text { participant }\end{array}$ \\
$\mathrm{D} /+$ : positive effect according to designer & $\mathrm{D} /-$ : effect to be improved according to designer \\
$\mathrm{A} /+$ : positive effect according to assessor & $\mathrm{A} /-$ : effect to be improved according to assessor \\
\hline
\end{tabular}

This table provides a quantified (and thus attenuating) outline of the information contained in the meta-analysis semantic database. Indeed, it is essential to be able to return to the recorded comments and the value judgements made. Some of this material will be used in our analysis of the principal features of the overview table. The measurement unit used corresponds to the number of recorded comments.

In fact, field surveys and modelling workshops are only regarded as high points in the approach by a small number of assessors. For this reason, we have not presented them in the overview table. An analysis of these results for the specific types of tools used (see Chapter 3 for their nomenclature) is presented in Chapter 7.

In view of the conventional tools and methods of the ComMod approach, it is not surprising to see that role-playing workshops (AJR) largely dominated the discussions (295 comments). This was a key point of most case studies during which the discussion forum was structured (E), interactions increased (I) and plural knowledge developed (S). This is above all the time during which atavisms are shaken and individual perceptions are broadened (V). Participants, designers and assessors confirmed the essential aspect: 'something' happens during the role-playing workshops. Paradoxically, some assessors seemed more critical than their sources of information and questioned the legitimacy (L) of the groups formed, most often regretting the absence of players regarded as legitimate, and, therefore, the quality of the discussion forum (E) created.

The second stage in order of importance (112 comments) was the design workshop (AC). This is an essential group phase during which the problem and system are considered jointly. Although this conceptual model can be implemented later in a simulation model or role-playing form, the essential aspect of the design workshop is to create this 'world view'. Each participant contributes to the common knowledge (S), the first interactions take place (I) and the discussion forum is established (E), sometimes with a few misunderstandings between participants and designers.

The prospective workshops (AP) formed a much more heterogeneous whole than the two previous cases. Indeed, they included both the exploration of management scenarios downstream of the two previous workshops, as well as the use of much more specific methods for case studies not normally called for in a ComMod approach. For example, the designers of case study 4 used a risk analysis matrix to explore as a group the implications of the various resource management modes. However, out of the 91 recorded comments, a balance can be established between favourable and unfavourable opinions, whatever the source of information. It seemed that the position of these workshops at the end of the project often drew criticism during an ex post assessment 
(13 case studies) from participants or designers frustrated at not being able to 'go further' in the process (Table 6.12).

Table 6.12. Different workshops and their effects.

\begin{tabular}{llllllllll}
\hline Identification workshop & P/+ & P/- & C/+ & C/- & E/+ & E/- & Total + & Total - & Total \\
\hline Creating knowledge (S) & 3 & & 1 & 4 & 1 & 1 & 5 & 5 & 10 \\
Enhancing interactions (I) & 1 & & 1 & & 2 & & 4 & 0 & 4 \\
Changing practices (P) & & & 1 & & & 1 & 1 & 1 & 2 \\
Modifying perceptions (V) & & & & & & & 0 & 0 & 0 \\
Creating discussion forums (E) & & 1 & 4 & 2 & 1 & & 5 & 3 & 8 \\
Enhancing legitimacy (L) & 5 & 3 & 3 & 1 & 1 & 2 & 9 & 6 & 15 \\
Securing independence (A) & & & & & & 1 & 0 & 1 & 1 \\
Total & 9 & 4 & 10 & 7 & 5 & 5 & 24 & 16 & 40 \\
\end{tabular}

\begin{tabular}{|c|c|c|c|c|c|c|c|c|c|}
\hline Designing workshop & $\mathbf{P} /+$ & $\mathbf{P} /-$ & $\mathrm{C} /+$ & $\mathrm{C} /-$ & E/+ & $\mathbf{E} /-$ & Total + & Total - & Total \\
\hline Creating knowledge (S) & 10 & 6 & 8 & 4 & 5 & & 23 & 12 & 35 \\
\hline Enhancing interactions (I) & 3 & 1 & 4 & & & & 12 & 1 & 13 \\
\hline Changing practices $(\mathrm{P})$ & 2 & & & & & & 5 & 0 & 5 \\
\hline Modifying perceptions (V) & 8 & 1 & & 1 & & & 8 & 2 & 10 \\
\hline Creating discussion forums (E) & 8 & 5 & 3 & & & 2 & 15 & 14 & 29 \\
\hline Enhancing legitimacy (L) & & 6 & & & 1 & 3 & 6 & 9 & 15 \\
\hline Securing independence (A) & 3 & & & 2 & & & 3 & 2 & 5 \\
\hline Total & & & & 14 & 18 & 7 & 72 & 40 & 112 \\
\hline Role-playing workshop & $\mathbf{P} /+$ & $\mathrm{P} /-$ & $\mathrm{C} /+$ & $\mathrm{C} /-$ & $\mathbf{E} /+$ & E/- & Total + & Total - & Total \\
\hline Creating knowledge (S) & & 7 & 15 & 2 & 7 & 2 & 39 & 11 & 50 \\
\hline Enhancing interactions (I) & & 8 & 5 & 3 & 7 & 9 & 30 & 20 & 50 \\
\hline Changing practices $(\mathrm{P})$ & 10 & 5 & 3 & 2 & 5 & 11 & 18 & 18 & 36 \\
\hline Modifying perceptions (V) & 16 & 5 & 6 & 1 & 3 & 1 & 25 & 7 & 32 \\
\hline Creating discussion forums (E) & 23 & 7 & 10 & 4 & 6 & 12 & 39 & 23 & 62 \\
\hline Enhancing legitimacy (L) & 3 & 8 & 2 & 7 & 4 & 15 & 9 & 30 & 39 \\
\hline Securing independence (A) & 4 & 8 & 2 & 3 & 6 & 3 & 12 & 14 & 26 \\
\hline Total & 91 & 48 & 43 & 22 & 38 & 53 & 172 & 123 & 295 \\
\hline Prospective workshop & $\mathbf{P} /+$ & $\mathbf{P} /-$ & $\mathrm{C} /+$ & $\mathrm{C} /-$ & $\mathbf{E} /+$ & E/- & Total + & Total - & Total \\
\hline Creating knowledge (S) & 3 & 4 & 3 & & 3 & 3 & 9 & 7 & 16 \\
\hline Enhancing interactions (I) & 3 & 1 & 2 & & 3 & 1 & 8 & 2 & 10 \\
\hline Changing practices $(\mathrm{P})$ & 1 & 3 & & 1 & & 2 & 1 & 6 & 7 \\
\hline Modifying perceptions (V) & 4 & 1 & 1 & & & & 5 & 1 & 6 \\
\hline Creating discussion forums (E) & 12 & 9 & & 4 & 2 & 2 & 14 & 15 & 29 \\
\hline Enhancing legitimacy (L) & 2 & 6 & 1 & 3 & & 6 & 3 & 15 & 18 \\
\hline Securing independence (A) & 1 & & 1 & 1 & 1 & 1 & 3 & 2 & 5 \\
\hline Total & 26 & 24 & 8 & 9 & 9 & 15 & 43 & 48 & 91 \\
\hline
\end{tabular}


The identification workshops (AI), although present in most projects, at least in the form of a launch workshop, were rarely considered by assessors as high points in the group approach (41 comments). However, the (rare) references underlined the importance of this initial phase in terms of the group's legitimacy (L) during its creation.

Overall, the same conclusions were reached in this workshop analysis as those drawn on the scale of the projects as a whole. The high points of the ComMod approach allow the creation of a discussion forum, facilitate interaction with other participants and generate group knowledge mostly in a relaxed atmosphere. However, various questions in connection with legitimacy were often raised in the assessments, which, it should once again be remembered, were largely conducted afterwards. The likely 'reconstruction' process, which often occurs in this kind of exercise, therefore, needs to be taken into account. However, the examination of the four case studies assessed along the way did not indicate any significant difference on this point compared with the other case studies.

Finally, the limited number of comments on changes in practices $(\mathrm{P})$ probably indicated the limits of the approach. Group decision-making requires more than just providing better information in a fairer way. This point is discussed further in the next section.

\section{Improving the current assessment protocol}

\section{Limitations of the current assessment protocol}

It should first be remembered that the assessment protocol had a twofold had to answer two questions:

- does the participation of stakeholders and researchers in a companion modelling process improve stakeholder involvement in group decisions concerning their management of renewable natural resources or not?

- if so, what are the components of the process (e.g. approach application contexts, combination of tools, etc.) that allow these results to be achieved? What improvements in the method are required to demonstrate its advantages and clarify its areas of validity?

Thus, the objective was not to assess the impact of ComMod approaches on the context, except from a sustainable development standpoint. The ADD-ComMod project was an exploratory phase in the assessment of a ComMod approach. The proposed assessment protocol (CP) is the result of a collective intention to understand what, in a ComMod project, produced a particular effect to improve and promote a given practice in support of sustainable development.

Two questionnaires were created: one for the project designers (DQ) and the other for the participants (PEG). Both questionnaires addressed social, cognitive, environmental and organizational issues. Any trends in the resource concerned or in the socio-political system were included in the participant forms. However, this information was not central to the processing of the resulting information. This last phase calls for a little more explanation. Why is this information not included?

The principle adopted in the protocol was to disaggregate the ComMod approach into meaningful sequences in terms of impact, and to compare the many methods and artefacts used in the 18 case studies. Applying ComMod principles, the CP is based on a simplified participatory approach model that defines the comparison framework: in a certain context, the designers organize, with participants, methods involving or 
establishing artefacts that promote interactions having effects on the participants and designers, which may even lead to a change of context (Figure 6.1).

Such simplification was needed in order to compare a large number of case studies. This simplicity, however, has a cost. Such a model does not reflect important dimensions in a companion modelling process. In this model, socio-economic factors and power relationships were part of the context and considered to be passive. Only the methods and artefacts used by designers produced effects, with the context merely influencing these effects. In practice, these methods are organized in time and place. Hutchins (1995) considered that any action takes place in a historical and cultural context. In this context, role-playing, plenary sessions and other group exercises for building a shared representation of the situation were carried out in specific places, before and after certain events and in a cultural and historical context. The influence of these parameters may be difficult to mainstream in a comparison exercise but become relevant in the monitoring and accurate assessment of each case study.

Furthermore, the linearity of the sequences of the theoretical model used does not reflect the complicated, multi-faceted and unpredictable dialogue processes (Beuret, 2006). In case study 10, for example, one series of dialogue workshops gave rise to several action offshoots: a complaint was filed in court and followed up by some stakeholders; another group tried to involve an influential personality from one of the villages concerned. Meanwhile, agricultural activities continued. Some of these action offshoots may or may not have contributed, later on, to solving the initial problem of irrigation management. The metaphor used by Beuret (2006) to describe this phenomenon is a tree offshoot. This image is appropriate except that the tree branches considered may sometimes join up and merge. In some cases, the iteration, sequence and/or combination of several trends and events, one of which may be linked to the ComMod approach, is more useful in explaining the effects observed.

Another limitation of the current protocol is the separation of those involved in these participatory processes into two main groups, the designers and the participants. Both groups were interviewed separately using different forms and the assessment focused on the distance between the intentions of the designers and the perception of the participants. Only the effects caused by the designers on the participants were registered. The effects caused by the designers because of their participation in the approach were not taken into account. In the $\mathrm{CP}$, the designers are not considered like all the other participants because of their involvement in the design of the participatory process; this distinction challenges ComMod principles.

\section{Improving the assessment protocol}

The results of the assessments conducted and their comparisons in the ADD-ComMod project now allow us to propose some pathways to improving the protocol. First, it is essential not only to focus on the participatory modelling process itself, but also on the context in which it takes place, and the eventual influences of one on the other.

The wide variety of possible situations in which the companion modelling approach is used and the wide variety of objectives invalidates the proposal of an assessment protocol based on a linear model of such an approach. This proposal, which was relevant in a comparative and exploration perspective, isn't suitable when it comes to monitoring specific case studies. On the basis of the experience of the 18 case studies assessed, we 
now propose the establishing of an assessment process that can be combined with the ComMod approach itself.

Such a mechanism should thus combine several dimensions: individual and collective dimensions; discrete and continuous gathering of information; procedural and contextual influences. It should include stakeholders in the design and implementation of the protocol and also be flexible and scalable over time according to changes in the social and environmental system concerned and the issues involved.

In several case studies, the assessors were asked to assess the effects of a series of events or interactions that took place several years ago. In practice, some tools have proven invaluable in analysing the dynamics involved and their satisfactory or unsatisfactory outcomes. In particular, keeping a project logbook was the most effective monitoring activity undertaken by some design teams (seven projects). This logbook took the form of a computer spreadsheet or just a simple notebook. This logbook should list all the events in the ComMod process. For each activity, the logbook should indicate the date, duration of the activity, organizer, participants, activity coordinator in the case of a group activity, type of activity, purpose, place, media used during the activity, sequence phase, and products of this activity (including the meeting reports, the intermediate objects obtained and the language used as the latter may significantly influence the involvement of a particular partner). For intermediate products and purposes, a physical link (in the case of a notebook, model, etc.) or a virtual link (for digital files) to the location of these products should be stipulated for ease of access.

However, keeping a logbook raises questions. Each of the seven logbooks produced and analysed during the ADD-ComMod project were kept by a single person, often the head of the design team. Many events in a ComMod process, however, happen in parallel or include only subgroups of stakeholders. To overcome this difficulty, an alternative system for recording events should supplement the logbook. Consideration could, for example, be given to a moral contract binding the stakeholders and project supervisor to setting up a simplified reporting system in the form of summary sheets, which would at least have the merit of briefly recording these aspects at regular intervals. This would provide regular 'snapshots' of the context and aspects and events that the participants considered important to record. The compilation of these snapshots taken from various viewpoints would provide a rich picture of events in and around the project, which can then be used in a more conventional ex post assessment.

In practice, the ComMod approach is structured around events bringing together participants, designers and observers. Role-playing, participatory modelling, discussions and other group activity sessions are organized during these events. It is essential to effectively assess these major events.

During the assessments carried out as part of the ADD-ComMod project, reports, minutes and verbatim accounts have proved invaluable. Written during, or immediately after events by a designer or an outside observer, these documents reflect the discussions, arguments, positions, alliances and power relationships between stakeholders, the technical choices made, the representation components considered, etc., or the minor events that punctuated the organization and the workflow of these major events. Several gathering levels and methods may be considered, but in all cases, the information must be gathered before, during and after the group interaction phase. Direct observation, whether by participants or otherwise (Arborio and Fournier, 1999), is one of the preferred 
survey techniques. It requires observer training and the setting up of an explicit observation chart that should be the same throughout the process, even if the observer is changed. Semi-structured individual or group interviews should also be conducted with participants to complete the data. Such interviews can be used to assess the learning achieved and changing perceptions in the social and environmental system considered. On the basis of a sample of participants, we thus recommend that three series of interviews should be carried out; the first before a major event, the second just after and the third some time later. A period of three weeks is proposed to allow for events to be discussed calmly. The topics discussed during these interviews should first be tailored locally to make sure that they are suited to the social and cultural characteristics of participants.

(i) Key aspects of the event.

(ii) Technical learning about the issue considered and the socio-political context.

(iii) Learning about personal and other participants' opinions and values.

(iv) Ability to think and act as a group.

(v) Appraisal of the methods implemented.

(vi) Development of group skills.

(vii) Asset sustaining activities.

(viii) Actions initiated and considered when returning to actual situations.

The information gathered at the end of these interviews should also be archived in the logbook. The compilation of these items in the logbook may be made available to an assessor to allow him to carry out a more conventional ex post analysis. It is considered that this will attenuate any limits observed with the current version of the CP. A systematic comparison of the logbooks for the various case studies should also be carried out to continue to critically examine and capitalize on the approach. Furthermore, it also seems desirable to include the participants themselves in drawing up and updating these logbooks to tackle the principle of post-normal research as defined by Funtowicz and Ravetz (1994).

\section{Questions about the implementation and use of the assessment}

Carrying out the assessments as part of the ADD-ComMod project has led to the formulation of new questions about conducting and using an assessment.

The first of these questions examines the relationship between the assessment and the ongoing participatory process. We believe that the results obtained during the interviews, the effects highlighted and the changing context can be mobilized as follows:

- to tailor the orientation and running of the process, in accordance with the needs and wishes of participants

- to improve current procedural aspects of the process (model, role-playing, logistics)

- to enrich the scientific understanding of the learning process (how to link the changes made to the project as a result of the results of ongoing assessments).

Another question raised during the project concerns the relationship between the designer of the activities, the project leader, the observer and the assessor. In practice, it is very difficult to coordinate the assessment of a major event directly with participant observation. While the conducting of surveys by the designer may solve certain obvious logistical problems, they may also give rise to a bias because of its 'identification' with workshops. The monitoring/assessment process that we have proposed must necessarily involve several people in a coordinated activity. How can the independence of observers 
be reconciled with the coordination of the designer's work? Should the non-neutrality called for in the ComMod Charter be applied to the assessor? What selection procedure should be used for an assessor who is both outside the project but has sufficient knowledge of the issues? What consideration should be given to the views of participants, which are sometimes contradictory to the ideas of the assessor and researchers? 